\title{
ChemFET sensor: Repercussion of Swift Heavy Ion irradiation on nanorods of nickel-based (NRs- Ni3HHTP2) Metal-Organic framework
}

Nikesh N. Ingle

Dr Babasaheb Ambedkar Marathwada University

Pasha Sayyad

Dr Babasaheb Ambedkar Marathwada University

Gajanan Bodkhe

Dr Babasaheb Ambedkar Marathwada University

Harshada Patil

Dr Babasaheb Ambedkar Marathwada University

Megha Deshmukh

Dr Babasaheb Ambedkar Marathwada University

Manasi Mahadik

Dr Babasaheb Ambedkar Marathwada University

\section{Sumedh Shirsat}

Jawaharlal Nehru College

Fouran Singh

Inter-University Accelerator Centre

Mahendra Shirsat ( $\nabla$ mdshirsat.phy@bamu.ac.in )

Dr Babasaheb Ambedkar Marathwada University https://orcid.org/0000-0002-4216-2919

\section{Research Article}

Keywords: Swift Heavy Ion (SHI), Metal-Organic Framework (MOF), Sensing, ChemFET study

Posted Date: February 25th, 2021

DOl: https://doi.org/10.21203/rs.3.rs-244931/v1

License: (c) (i) This work is licensed under a Creative Commons Attribution 4.0 International License.

Read Full License

Version of Record: A version of this preprint was published at Journal of Materials Science: Materials in Electronics on July 2nd, 2021. See the published version at https://doi.org/10.1007/s10854-021-06353-z. 



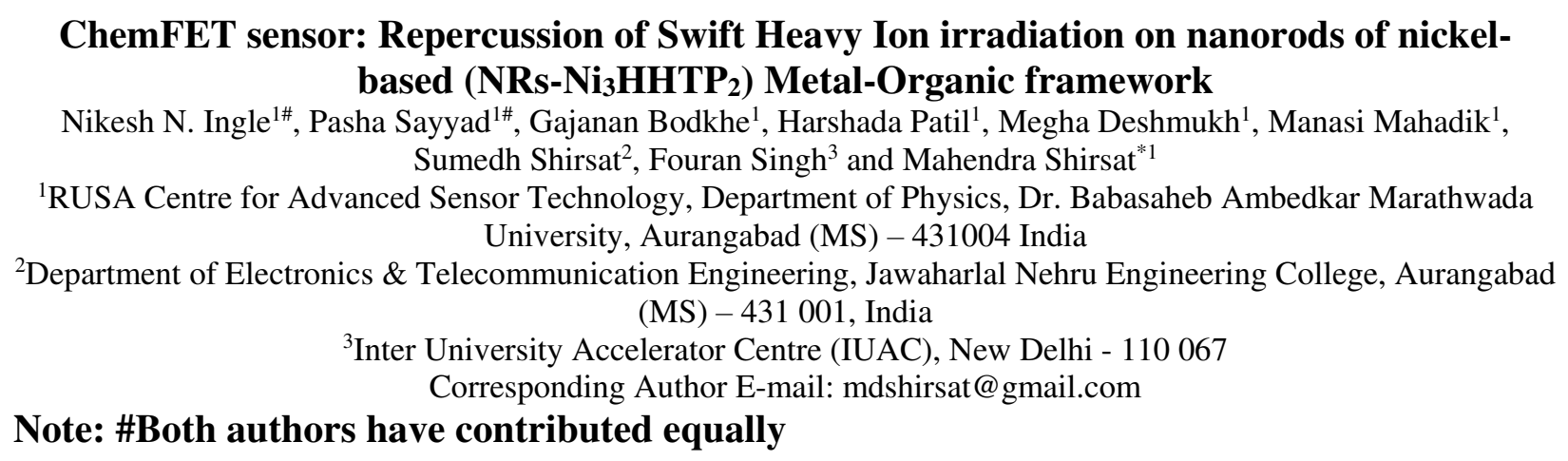

\section{ChemFET sensor: Repercussion of Swift Heavy Ion irradiation on nanorods of nickel-}

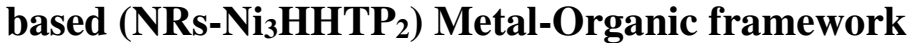

Nikesh N. Ingle ${ }^{1 \#}$, Pasha Sayyad ${ }^{1 \#}$, Gajanan Bodkhe ${ }^{1}$, Harshada Patil ${ }^{1}$, Megha Deshmukh ${ }^{1}$, Manasi Mahadik ${ }^{1}$, Sumedh Shirsat ${ }^{2}$, Fouran Singh ${ }^{3}$ and Mahendra Shirsat ${ }^{* 1}$

${ }^{1}$ RUSA Centre for Advanced Sensor Technology, Department of Physics, Dr. Babasaheb Ambedkar Marathwada University, Aurangabad (MS) - 431004 India

${ }^{2}$ Department of Electronics \& Telecommunication Engineering, Jawaharlal Nehru Engineering College, Aurangabad (MS) - 431 001, India

${ }^{3}$ Inter University Accelerator Centre (IUAC), New Delhi - 110067

Note: \#Both authors have contributed equally

Corresponding Author E-mail: mdshirsat@gmail.com

\section{Abstract:}

Repercussion of Swift Heavy Ion (SHI) irradiation on nickel-based nanorods of MetalOrganic Framework (NRs-Ni3 HHTP 2 -MOF) for enhancement in the properties of ChemFET based gas sensor has been investigated. Nanorods of $\mathrm{Ni}_{3} \mathrm{HHTP}_{2}-\mathrm{MOF}$ were synthesized by chemical method and exposed to $C^{12+}$ ions irradiation with fluence $1 \times 10^{11} \mathrm{ion} / \mathrm{cm}^{2}$ and $1 \times 10^{12}$ ion $/ \mathrm{cm}^{2}$. The structural, spectroscopic morphological and optical characterizations were carried out using x-ray diffraction (XRD), fourier transfer infrared spectroscopy (FTIR), atomic force microscopy (AFM) with scanning electron microscopy (SEM) and UV-visible spectroscopy were studied respectively. Whereas the bandgap was calculated from Tauc's plot. The synthesized nanorods of $\mathrm{Ni}_{3} \mathrm{HHTP}_{2} \mathrm{MOF}$ were drop-casted on gold coated microelectrodes on silicon/silicon dioxide $\left(\mathrm{Si} / \mathrm{SiO}_{2}\right)$ substrate, where silicon layer serves as a gate and gold microelectrodes on silicon/silicon dioxide $\left(\mathrm{Si} / \mathrm{SiO}_{2}\right)$ substrate as a source and drain. The transmutations in material properties due to SHI irradiations were serviceable for enhancing field-effect transistor (transfer and output) properties.

Keywords: Swift Heavy Ion (SHI), Metal-Organic Framework (MOF), Sensing, ChemFET study

\section{Introduction}

In the last few years, the Metal-organic framework (MOF) is one of the focusing materials in the research world due to its tunable properties. MOFs are ultra-high porous, large surface area, highly crystalline, high stability material and importantly it can be tunable by altering central metal or organic ligands[1-3]. MOFs are helpful in various applications like gas storage, sensor, chemical separations, biomedical imaging, catalysis and drug delivery as precursors for cooking graphite and metal oxides materials $[1,2,4]$.

The most critical problem in front of modern society is a continuous increment in pollutions in terms of air, water, sound etc[5-7]. Among these air pollution absorbed through the respiratory system. Above permissible exposure limit (PEL), hazardous gases responsible for immediately life-threatening[8]. Sulfur dioxide is one of the responsible gases for increasing cardiorespiratory mortality and morbidity in human beings as well as the creation of corrosion in nonliving things $[8,9]$. Therefore, researchers have been focusing on enhancing sensing properties of detectors for detection various gases including $\mathrm{SO}_{2}$ [10-12]. Since last few years, MOF has been one of the mostly explored materials for detection various gases including $\mathrm{SO}_{2}$. M. Tchalala[13] et al. reported fluorinated metal-organic frameworks (MOFs) used for the selective removal and 
sensing of $\mathrm{SO}_{2}$ analytes. Therefore, screening of new materials and their modification for enhancing sensing properties are continuous process in the research area.

Since the last few decenniums, sundry materials have been modified extensively by high energy particles (electron, proton) of heavy ions[14-17]. The irradiation of energetic ion beams were engenders several types of defects in materials like chain scission, ionization or excitation and ion track formation etc. The SHI irradiation is one of the promising implements for material modifications and workable for enhancing electrical properties[18, 19]. Zhang et al.[19] studied the performance of SHI irradiated $\mathrm{MoSe}_{2}$ material. The electrical changes were observed by using TMDC-channel field-effect transistors (FETs). Zeng et al.[20] explored the effects of electrical properties in graphene devices by exposing it to energetic ion beam irradiation where graphene was irradiated by $1.79 \mathrm{GeV}$ Ta ions. It was observed that SHI irradiated graphene at lower fluence exhibited optimized field-effect transistors performance, whereas, at higher fluence, devices were significantly depreciated electrical properties after the irradiation process. Also, Manikanthababu et al.[21] reported electrical characterization of vertical Schottky barrier diodes (SBDs) based on $\mathrm{Ag}$ ion irradiated $\mathrm{Ni} / \beta-\mathrm{Ga}_{2} \mathrm{O}_{3}$ materials with $120 \mathrm{MeV}$.

To date, researchers have explored SHI irradiation for modification of properties of various materials like Conducting Polymers (CPs), Single-Walled Carbon Nanotubes (SWNTs), Graphene (Gr), Metal Oxides (MOs) etc by using various SHI and fluence rate[22-25]: Researchers have also explored SHI irradiation on various MOF materials, R. Dutta et al.[26] have reported SHI irradiation on NiBTC MOF using $100 \mathrm{MeV} \mathrm{O}^{7+}$, which exhibited enhancement in electrochemical sensing properties. Recently P. Sayyad et al.[27] studied the effect of $\mathrm{Au}$ ion with $100 \mathrm{MeV}$ at fluence $1 \times 10^{11} \mathrm{ion} / \mathrm{cm}^{2}$ and $1 \times 10^{12} \mathrm{ion} / \mathrm{cm}^{2}$ irradiation on FeBTC MOF. They observed drastic changes for higher ion fluence rate. Moreover, decrease in crystallite size, increase of energy bandgap, decrease in average surface roughness and new functional group $(\mathrm{C}-\mathrm{H})$ was observed after SHI irradiation at a higher fluence $1 \times 10^{12} \mathrm{ion} / \mathrm{cm}^{2}$.

Recently, we have explored nickel-based NRs- $\mathrm{Ni}_{3} \mathrm{HHTP}_{2} \mathrm{MOF}$ for detection sulfur dioxide $\left(\mathrm{SO}_{2}\right)$ using ChemFET modality [28]. However, to the best of our knowledge the influence SHI irradiation for enhancing properties of materials for ChemFET sensing has not been explored so far. In the present work, SHI irradiation has been explored to enhance the ChemFET sensing properties of NRs- $\mathrm{Ni}_{3} \mathrm{HHTP}{ }_{2} \mathrm{MOF}$ using $\mathrm{C}^{12+}$ ion with fluence rate $1 \times 10^{11}$ and $1 \times 10^{12} \mathrm{ion} / \mathrm{cm}^{2}$

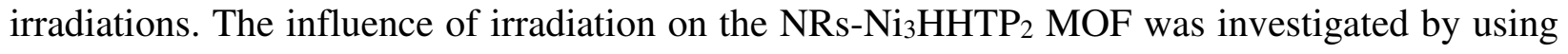
structural analysis, surface morphological, electrical and optical properties.

\section{Experimental details}

\subsection{Fabrication of Microelectrode}

The device platform was prepared by using a typical photolithography process as reported earlier[29]. Highly boron (B) doped silicon ( $\mathrm{Si}$ ) substrate having p-type nature with thickness $525 \mu \mathrm{m}$ performed as a back gate terminal in FET measurement. A $100 \mathrm{~nm}$ thick $\mathrm{SiO}_{2}$ layer was deposited on the Si substrate by low pressure chemical vapor deposition. It is followed by deposition $\mathrm{Cr}$ layer $(20 \mathrm{~nm})$ and Au layer $(120 \mathrm{~nm})$ by e-beam evaporator and standard lift-off technique. The width of $\mathrm{Au}$ micro electrodes was $200 \mu \mathrm{m}$ and the gap between two micro 
electrodes was $3 \mu \mathrm{m}$. Later micropatterned substrates were immersed in piranha solution $(70 \%$ concentration $\mathrm{H}_{2} \mathrm{SO}_{4} / 30 \% \mathrm{H}_{2} \mathrm{O}_{2}$ ) followed by rinsing and drying under $\mathrm{N}_{2}$ flow before use.

\subsection{Synthesis of NRs-Ni ${ }_{3} \mathrm{HHTP}_{2} \mathrm{MOF}$}

Nickel (II) acetate (tetrahydrate) (99.99\%, purchased from Sigma Aldrich) was used without further purification along with 2,3,6,7,10,11-Hexahydroxytripenylne Hydrate (HHTP) (98\%, purchased from TCI). The chemical method followed for synthesis of NRs-Ni3HHTP2 MOF. Before mixing both chemicals, $2.63 \mathrm{mmol}$ nickel (II) acetate (tetrahydrate) was continuously stirred with $4 \mathrm{ml}$ deionized water. Further addition of $1.31 \mathrm{mmol}$ HHTP in continuously stirred chemical with continuous heating at $90^{\circ} \mathrm{C}$ for $8 \mathrm{hrs}$ was provided. The chemically synthesized $\mathrm{NRs}_{-} \mathrm{Ni}_{3} \mathrm{HHTP}_{2}$ solution was drop casted between two gold microelectrodes which was dried in room atmospheric conditions.

\subsection{SHI irradiation}

The SHI irradiation was carried out by using material science beamline, 15UD Pelletron tandem accelerators at the Inter-University Accelerator Center, New Delhi, India. The scanning area of ion irradiation was $1 \times 1 \mathrm{~cm}^{2}$ of devices riding on a ladder which was placed in the irradiated vacuum chamber under $10^{-6}$ mbar pressure. The targeted material irradiated with $\mathrm{C}^{12+}$ ion with $50 \mathrm{MeV}$ at $1 \mathrm{pnA}$ for fluence $1 \times 10^{11} \mathrm{ion} / \mathrm{cm}^{2}$ and $1 \times 10^{12} \mathrm{ion} / \mathrm{cm}^{2}$.

The value electronic stopping, nuclear stopping and range of ions in NRs- $\mathrm{Ni}_{3} \mathrm{HHTP}_{2}$ were calculated by using the SRIM simulator program. The calculated values were $1647 \mathrm{eV} / \AA$, $10.84 \mathrm{eV} / \AA$ and $10.25 \mu \mathrm{m}$ respectively.

\subsection{Material characterizations}

The X-Ray diffraction (XRD) was carried out using Bruker D8 Advance having potential difference $40 \mathrm{kV}$ and current 40kA with source $\mathrm{CuKa}$ (wavelength 1.5406Å). The FTIR spectrum was recorded using Bruker Alpha ATR. For surface morphology, Scanning Electron Microscopy (SEM) and Atomic Force Microscopy (AFM) were carried out by Tescan MIRA 3 LMH and Park XE-7 instruments respectively and UV-Vis spectroscopy done by using Jasco V-750. FET measurements were carried out using Keithley 4200A semiconductor parameter analyzer (SPA).

Sensing measurements were performed using indigenously developed dynamic gas sensing setup which was attached with corrosive and non-corrosive mass flow controllers (MFCs) and data performance was recorded using Keithley 4200A. Tedlar bags were used to get the desired concentration of gas analyte.

\section{Results and discussion}

\subsection{Structural Characterization}

The structural analysis of pristine and SHI irradiated NRs- $\mathrm{Ni}_{3} \mathrm{HHTP}_{2} \mathrm{MOF}$ was carried

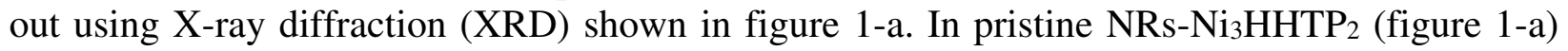
(black) exhibits $2 \theta$ peaks at $5^{\circ}$ and $9.4^{\circ}$ and matches with reported data [26] which is consistent to (100) and (020) Miller indices respectively. The percentage of crystallinity for pristine NRs$\mathrm{Ni}_{3} \mathrm{HHTP}_{2}$ is $48 \%$. After $\mathrm{C}^{12+}$ ion irradiation, $2 \theta$ angle peak intensity decreases with increasing 


\begin{tabular}{|l|l|l|l|l|l|l|l|}
\hline Materials & $2 \theta^{0}$ & $\begin{array}{l}\text { FWHM } \\
\beta\end{array}$ & $\begin{array}{l}\text { Crystallite } \\
\text { size D }(\AA)\end{array}$ & $\begin{array}{l}\text { Micro } \\
\text { strain }(\varepsilon)\end{array}$ & $\begin{array}{l}\text { dislocation } \\
\text { density }(\delta) \\
\left(\mathrm{X} 10^{-21}\right)\end{array}$ & $\begin{array}{l}\text { distortion } \\
\text { parameter }(\mathrm{g})\end{array}$ & $\begin{array}{l}\text { interchain } \\
\text { separation }(\mathrm{R})\end{array}$ \\
\hline $\mathrm{NRs}^{-\mathrm{Ni}_{3} \mathrm{HHTP}_{2}}$ & 4.515 & 0.346 & 705.2 & 0.0862232 & 1.537 & 4.381965552 & 12.2316438 \\
\hline $\begin{array}{l}1 \mathrm{x} 10^{11} \\
\mathrm{ion} / \mathrm{cm}^{2}\end{array}$ & 4.515 & 0.406 & 658.3 & 0.1011752 & 2.11 & 5.141843972 & 12.2316438 \\
\hline $\begin{array}{l}1 \times 10^{12} \\
\text { ion } / \mathrm{cm}^{2}\end{array}$ & 4.515 & 0.420 & 615.6 & 0.104664 & 2.257 & 5.319148936 & 12.2316438 \\
\hline
\end{tabular}

153 fluence rate. The resultant distinct $2 \theta$ peaks were observed after irradiation materials at $46^{\circ}$ and $48^{\circ}$. The percentage of crystallinity after $\mathrm{C}^{12+}$ irradiation for fluence rate $1 \times 10^{11}$ (figure 1 -a (red)) and $1 \times 10^{12}$ ion $/ \mathrm{cm}^{2}$ (figure 1 -a (blue) was $23 \%$ and $20 \%$ respectively. This result confirms the crystal structure collapse with increase in amorphous phase after SHI irradiation.

Besides giving crystalline structure information, the peaks of the diffraction pattern provide valuable information in other aspects of the material. The crystalline size of pristine and SHI irradiated NRs-Ni3 $\mathrm{HHTP}_{2}$ was calculated by using the Debye-Scherrer's formula in equation (I) at $2 \theta$ angle $4.515^{\circ}$.

$$
D=\frac{0.9 \lambda}{\beta \cos \theta}
$$

where as $\mathrm{D}$ is crystallite size, $\lambda$ is the wavelength of $\mathrm{x}$-ray source radiation i.e. $\mathrm{CuK}_{\alpha}$ wavelength is $1.5406 \AA, \beta$ is full width at half maxima (FWHM) calculated from Gauss fitting and $\theta$ is the Braggs angle of diffraction. Also, the dislocation density $(\delta)$ (equation II), distortion parameter (g) (equation III), and inter-chain separation (R) (equation IV) were shown in table 1. The crystallite size of pristine NRs- $\mathrm{Ni}_{3} \mathrm{HHTP}_{2}$ was $705.2 \AA$ decreased $658.3 \AA$ and $615.6 \AA$ with fluence rate $1 \times 10^{11}$ and $1 \times 10^{12} \mathrm{ion} / \mathrm{cm}^{2}$ respectively. Also, it is interesting to see that the microstrain increases with increasing fluence rate.

$\delta=\frac{1}{D^{2}}$ .. II

$g=\frac{\beta}{\tan \theta}$ III

$\mathrm{R} \frac{5 \lambda}{8 \sin \theta}$ IV
Table 1: XRD parameter calculated for pristine and irradiated NRs-Ni3HHTP2 MOF materials.

\subsection{Spectroscopy analysis}

Fourier Transfer Infrared spectroscopy (FTIR) spectrums were recorded for pristine and irradiated NRs-Ni3 $\mathrm{HHTP}_{2}$ MOF materials in ZnSe window having range $4000-500 \mathrm{~cm}^{-1}$ shown in the figure 1-b. The bands $700-900 \mathrm{~cm}^{-1}$ shows continuous stretching containing $\mathrm{CH}_{3}-\mathrm{metal}$ group due to $\mathrm{CH}_{2}$ rocking vibration present in $\mathrm{NRs}_{-} \mathrm{Ni}_{3} \mathrm{HHTP}_{2} \mathrm{MOF}$. $\mathrm{C}=\mathrm{C}$ stretching vibration bonds represent in between $1500-1580 \mathrm{~cm}^{-1}$. Whereas $\mathrm{O}-\mathrm{H}$ stretching vibration present in the $3200-3700 \mathrm{~cm}^{-1}$ range. In the case of irradiated NRs-Ni3HHTP 2 MOF materials, some of the bands become narrow and intensity decreases, these change are attributed to the scissoring and 
crosslinking of material by ion beam irradiation[30]. This fact might be responsible for the amorphous nature of $\mathrm{NRs}-\mathrm{Ni}_{3} \mathrm{HHTP}_{2} \mathrm{MOF}$ materials after irradiation.
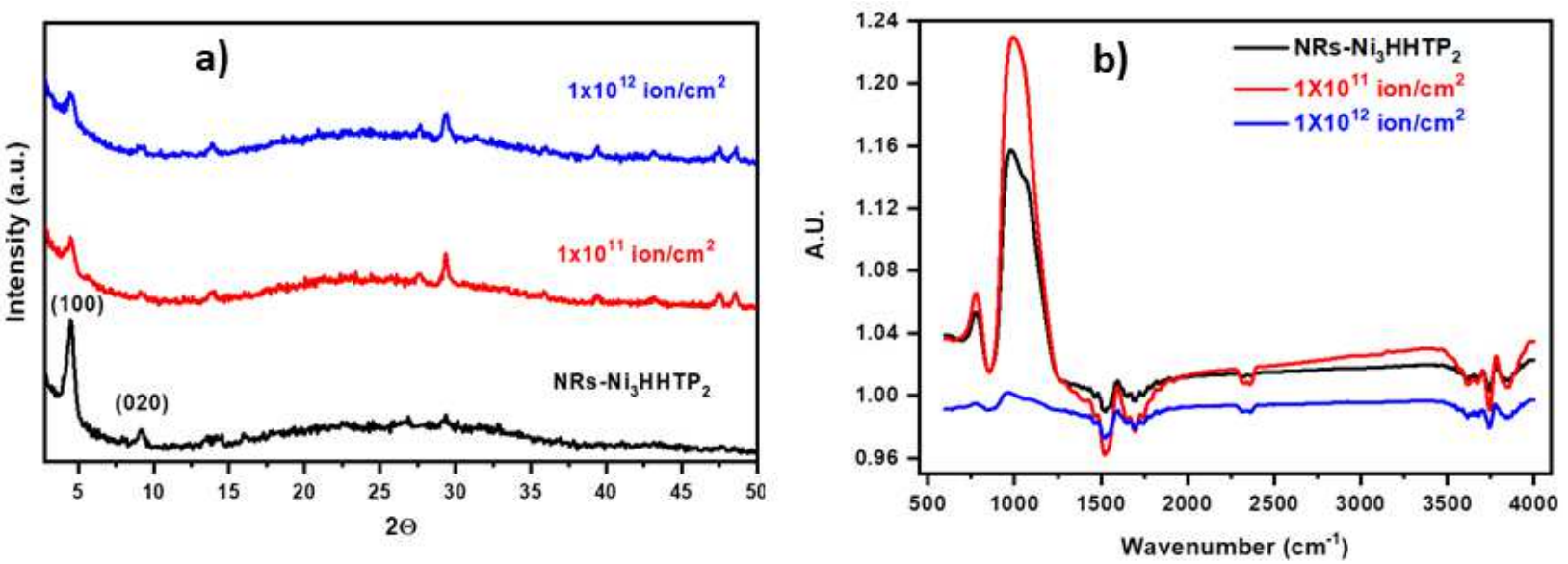

Figure 1: a) XRD patterns and b) FTIR spectrum of pristine (black) and $\mathrm{C}^{12+}$ ion irradiation with fluence rate $1 \times 10^{11} \mathrm{ion} / \mathrm{cm}^{2}$ (red) and $1 \times 10^{12} \mathrm{ion} / \mathrm{cm}^{2}$ (blue) on NRs-Ni3HHTP 2 MOF materials.

\subsection{Morphological studies}

Scanning electron microscopy (SEM) images were recorded before and after $\mathrm{C}^{+12}$ ion with fluence rate of $1 \times 10^{11}$ and $1 \times 10^{12} \mathrm{ion} / \mathrm{cm}^{2}$ irradiation on $\mathrm{NRs}-\mathrm{Ni}_{3} \mathrm{HHTP}_{2} \mathrm{MOF}$ shown in figure 2 (a, b and c) respectively. This confirms the presence of nano-rods in synthesized $\mathrm{Ni}_{3} \mathrm{HHTP}_{2}$ MOF. The average size of nano-rods (pristine $\mathrm{Ni}_{3} \mathrm{HHTP}_{2}, 38 \mathrm{~nm}$ ) decreases with fluence rate i.e. $\mathrm{C}^{12+}$ with fluence rate $1 \times 10^{11}$ and $1 \times 10^{12} \mathrm{ion} / \mathrm{cm}^{2}, 35 \mathrm{~nm}$ and $28 \mathrm{~nm}$ respectively. This was done due to the high energetic ion passed through materials which loses electronic energy and creates defects [23]. An increased influence rate shows more clusters which are attributed to scissoring and crosslinking of material and is in good agreement with XRD and FTIR results.

Atomic force microscopy (AFM) was carried out (shown in figure 2 (d, e and f)) for determination of roughness (shown in figure $2(\mathrm{~g}, \mathrm{~h}$ and $\mathrm{i})$ ) of pristine and SHI irradiated $\mathrm{C}^{12+}$ with fluence rate $1 \times 10^{11}$ and $1 \times 10^{12} \mathrm{ion} / \mathrm{cm}^{2}$ on $\mathrm{NRs}-\mathrm{Ni}_{3} \mathrm{HHTP} \mathrm{P}_{2} \mathrm{MOF}$ respectively. The roughness was calculated by XEI image processing software. The roughness of pristine NRs$\mathrm{Ni}_{3} \mathrm{HHTP}_{2} \mathrm{MOF}$ was $32.518 \mathrm{~nm}$ and roughness after $\mathrm{C}^{12+}$ ion irradiated sample was $20.053 \mathrm{~nm}$ and $19.475 \mathrm{~nm}$ with fluence rate $1 \times 10^{11}$ and $1 \times 10^{12} \mathrm{ion} / \mathrm{cm}^{2}$ respectively. The decrease in surface roughness is due to discontinuous tracks and the creation of defects after irradiation of high energetic ion. Higher fluence creates more clusters in material which reduces the surface roughness as compared to lower fluence. 

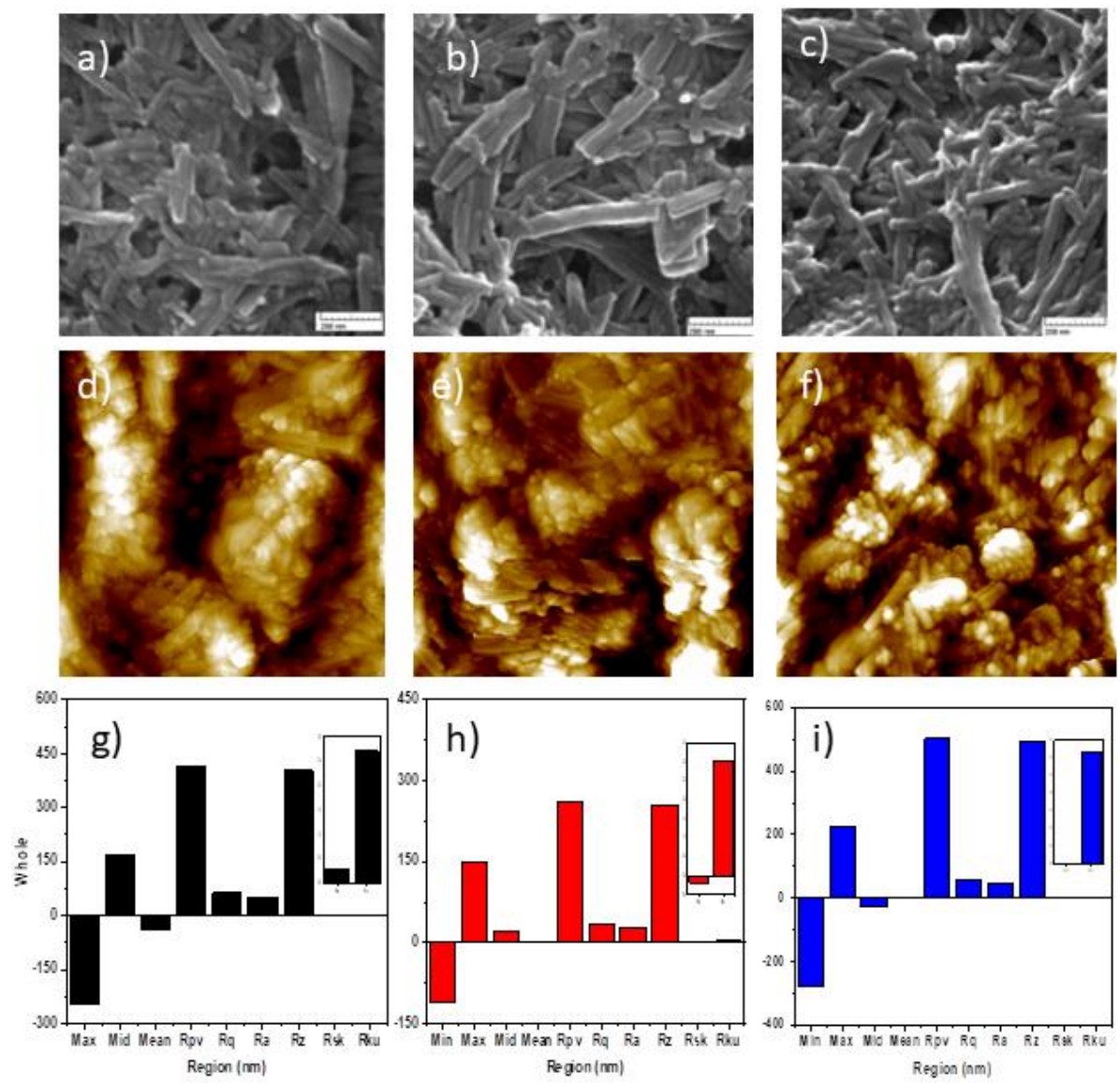

Figure 2: SEM images ( $a, b$ and $c$ ) and AFM images (d, e and $\mathrm{f}$ ) with surface roughness ( $\mathrm{g}, \mathrm{h}$ and

i) for pristine (black) and $\mathrm{C}^{12+}$ ion irradiation with fluence rate $1 \times 10^{11} \mathrm{ion} / \mathrm{cm}^{2}$ (red) and $1 \times 10^{12}$

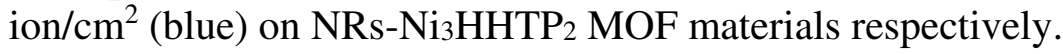

195

196

197

198

199

200

201

202

203

204

205

206

207

208

209

210

\subsection{Optical Studies}

The optical absorbance spectra of pristine (black) and $\mathrm{C}^{12+}$ irradiated with fluence rate $1 \times 10^{11}$ ion $/ \mathrm{cm}^{2}$ (red) and $1 \times 10^{12} \mathrm{ion} / \mathrm{cm}^{2}$ (blue) on NRs-Ni3HHTP 2 MOF shown in figure 3 . It was observed that the pristine $\mathrm{NR}-\mathrm{Ni}_{3} \mathrm{HHTP}_{2}$ and irradiated materials absorbance peaks are in the 400-550 nm visible wavelength range. The intensity reduction was observed in irradiated materials. The bands at 450-500 nm have been frequently associated with defect absorption[31]. This was due to the creation of free radicals and ions form by irradiation on NRs- $\mathrm{Ni}_{3} \mathrm{HHTP}_{2}$ materials. It has affected the bandgap of materials. The bandgap of pristine NRs-Ni3 $\mathrm{HHTP}_{2}$ was $3.54 \mathrm{eV}$, after $\mathrm{C}^{+12}$ ion irradiation band gap decreases. It was $3.41 \mathrm{eV}$ and $3.44 \mathrm{eV}$ for fluence rate of $1 \times 10^{11} \mathrm{ion} / \mathrm{cm}^{2}$ and $1 \times 10^{12}$ ion $/ \mathrm{cm}^{2}$ respectively shown in figure 3 (b-1, b-2 and b-3). This was due to the creation of pronounced coalescence phenomena in higher fluence $\left(1 \times 10^{12}\right.$ ion $/ \mathrm{cm}^{2}$ ) irradiated material[32]. It shows complementary results with structural and morphological characteristics. Due to high energy, a little bit more damage was created in the material. 

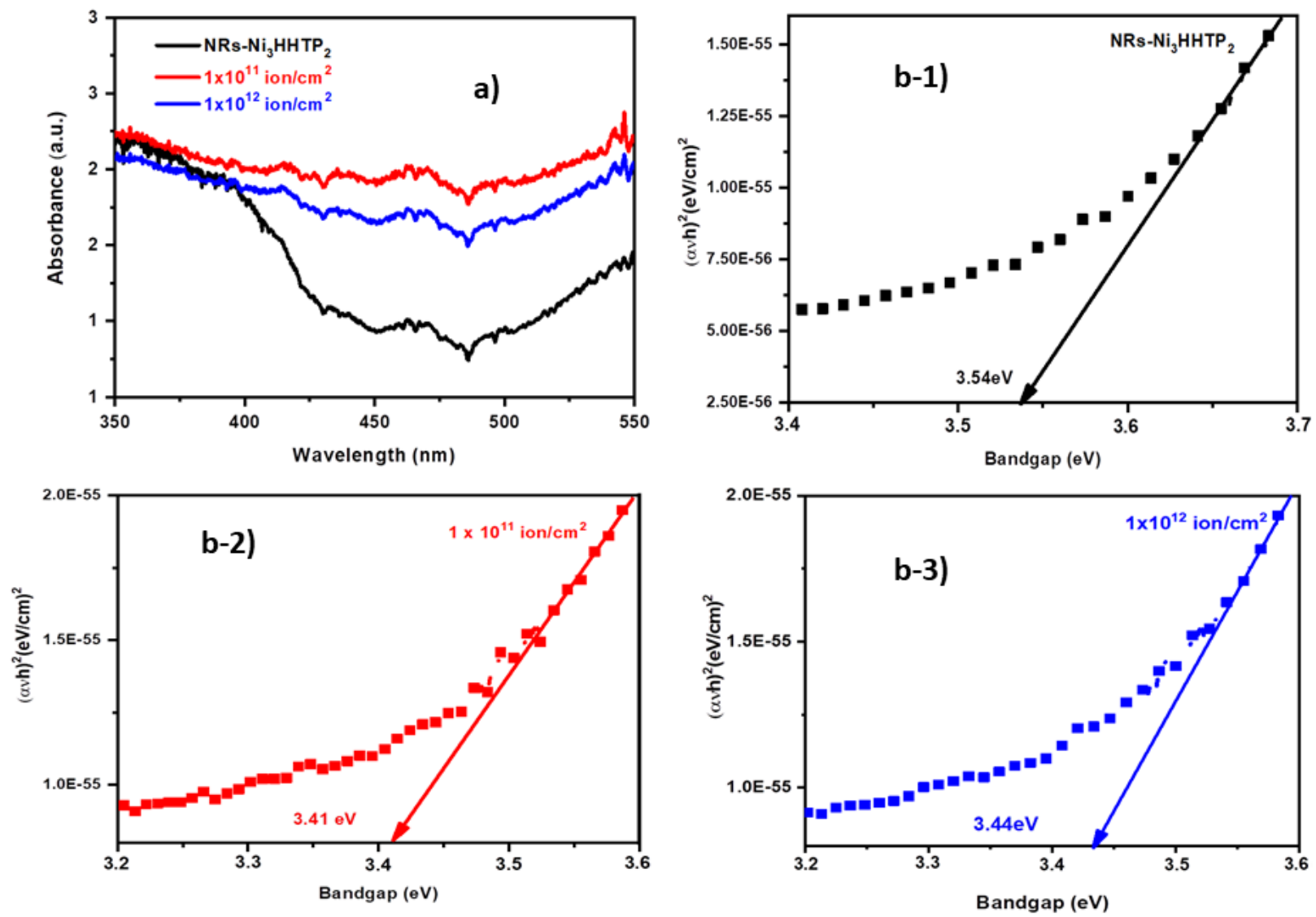

211

212

213

214

215

216

217

218

219

220

221

\section{2}

223

224

225

226

227

228

229

Figure 3: a) UV-Vis absorbance spectra with Tauc's plots (b-1, b-2 and b-3) of pristine (black) and $\mathrm{C}^{12+}$ irradiation with fluence rate $1 \times 10^{11}$ (red) and $1 \times 10^{12} \mathrm{ion} / \mathrm{cm}^{2}$ (blue) on NRs-Ni3HHTP 2 MOF.

The bandgap was calculated by using Tauc's equation (II).

$\alpha=2.303 \frac{A}{d}$

$\alpha h v=B\left(h v-E_{g}\right)^{1 / 2}$

where $\mathrm{Eg}$ is an energy bandgap of the material, $\alpha$ is the coefficient of absorbance calculated from equation (III), $\mathrm{A}$ is absorbance and $\mathrm{d}$ is the thickness of deposited material.

\section{Field Effect Transistor (FET) measurements}

The FET measurements were carried out by measuring the output and transfer characteristics of pristine and irradiated MOFs. Output characteristics were performed by modulating drain to source voltage $\left(\mathrm{V}_{\mathrm{ds}}\right)$ in the window 0 to $10 \mathrm{~V}$ at gate voltage $\left(\mathrm{V}_{\mathrm{gs}}\right) 1$ to $4 \mathrm{~V}$ for NRs-Ni3HHTP2 MOF shown in figure 4-a whereas for $\mathrm{C}^{+12}$ ion irradiated MOF materials output characteristics were performed by keeping same $\mathrm{V}_{\mathrm{ds}}$ window at constant gate voltage $\left(\mathrm{V}_{\mathrm{gs}}\right) 1 \mathrm{~V}$ as shown in figure 4-b. Moreover, transfer characteristics (as shown in figure 4-c) were measured by modulating gate to source voltage in window -30 to $30 \mathrm{~V}_{\mathrm{gs}}$ at $\mathrm{V}_{\mathrm{ds}}=0.5 \mathrm{~V}$. Excellent 
ON/OFF behavior of FET was observed. The significant changes in output and transfer characteristics in pristine and SHI irradiated device were observed. Significant enhancement in drain current $\left(\mathrm{I}_{\mathrm{ds}}\right)$ was observed in SHI irradiated MOF materials. This is due to SHI induced defects and the creation of free radicals and ions in irradiated MOF. The SHI enhances charge transportation in irradiated MOF materials.
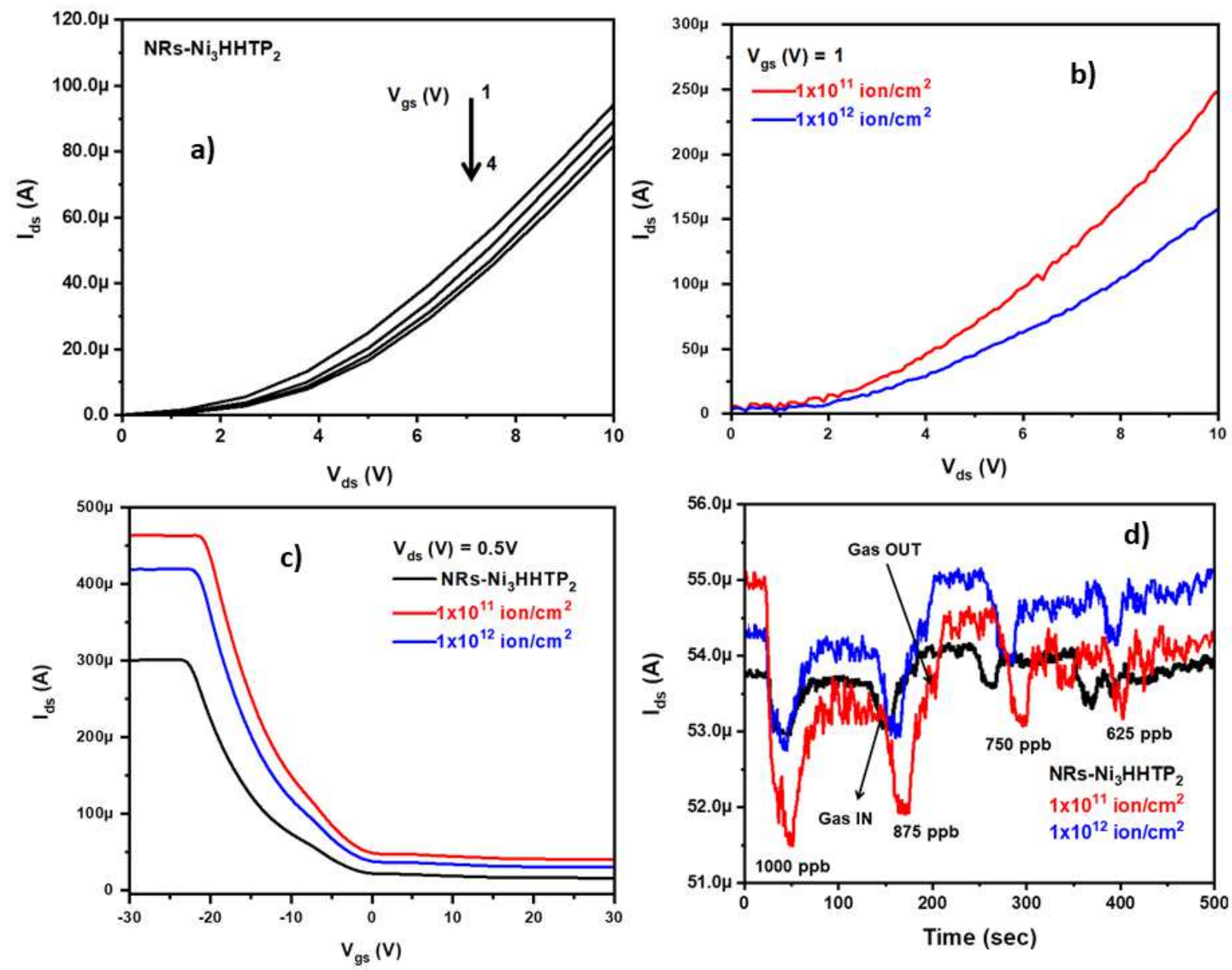

235

236

237

238

239

240

241

242

243

244

245

246

Figure 4: FET measurements i.e. Output characteristics for a) NRs-Ni3HHTP 2 MOF and b) after $\mathrm{C}^{+12}$ ion irradiation on MOF material whereas c) transfer characteristics, d) ChemFET sensing for $\mathrm{SO}_{2}$ analytes.

\section{ChemFET sensing}

The NRs-Ni3 HHTP 2 and $\mathrm{C}^{+12}$ ion irradiated with fluence $1 \times 10^{11} \mathrm{ion} / \mathrm{cm}^{2}$ and $1 \times 10^{12}$ ion $/ \mathrm{cm}^{2}$ devices were tested in ChemFET modality for detection of $\mathrm{SO}_{2}$ gas analytes from 1000 ppb to $625 \mathrm{ppb}$ levels by keeping $\mathrm{V}_{\mathrm{gs}}=1 \mathrm{~V}$ and $\mathrm{V}_{\mathrm{ds}}=0.5 \mathrm{~V}$ constant as shown in figure 4-d. Reversible ChemFET sensing was observed for $\mathrm{SO}_{2}$ gas analytes. It was showing remarkable dynamic sensing response against $\mathrm{SO}_{2}$ analytes. The significant improvement in the sensing performance was observed in case of SHI irradiated MOF. The enhancement in sensing 
performance may be attributed to the increased active sites for $\mathrm{SO}_{2}$ adsorption on MOF after SHI irradiation. The statistical approach for calculating sensitivity for $\mathrm{SO}_{2}$ analytes was adopted by using linear regression equations and normalized current responses are plotted against gas concentrations for pristine and SHI irradiated MOF as shown in figure 5-a. For NRs-Ni $\mathrm{HHTP}_{2}$ MOF linear regression equation was $\mathrm{y}=0.0018 \mathrm{x}-1.009$ with sensitivity 0.785 . Moreover, for SHI irradiated MOF ( $\mathrm{C}^{+12}$ ion irradiated MOF with fluence $1 \times 10^{11} \mathrm{ion} / \mathrm{cm}^{2}$ and $1 \times 10^{12} \mathrm{ion} / \mathrm{cm}^{2}$ ) linear regression equation were $\mathrm{y}=0.0018 \mathrm{x}-0.675$ with sensitivity 0.931 and $\mathrm{y}=0.0014 \mathrm{x}-$ 0.588 with sensitivity 0.9142 respectively. The $\mathrm{C}^{+12}$ ion irradiated MOF with fluence $1 \times 10^{11}$ ion $/ \mathrm{cm}^{2}$ shows excellent (0.931) sensitivity. On that line, repeatability was tested for $1000 \mathrm{ppb}$ using $\mathrm{C}^{+12}$ ion irradiated MOF with fluence $1 \times 10^{11} \mathrm{ion} / \mathrm{cm}^{2}$ as shown in figure $5-\mathrm{b}$ and it shows excellent repeatability.
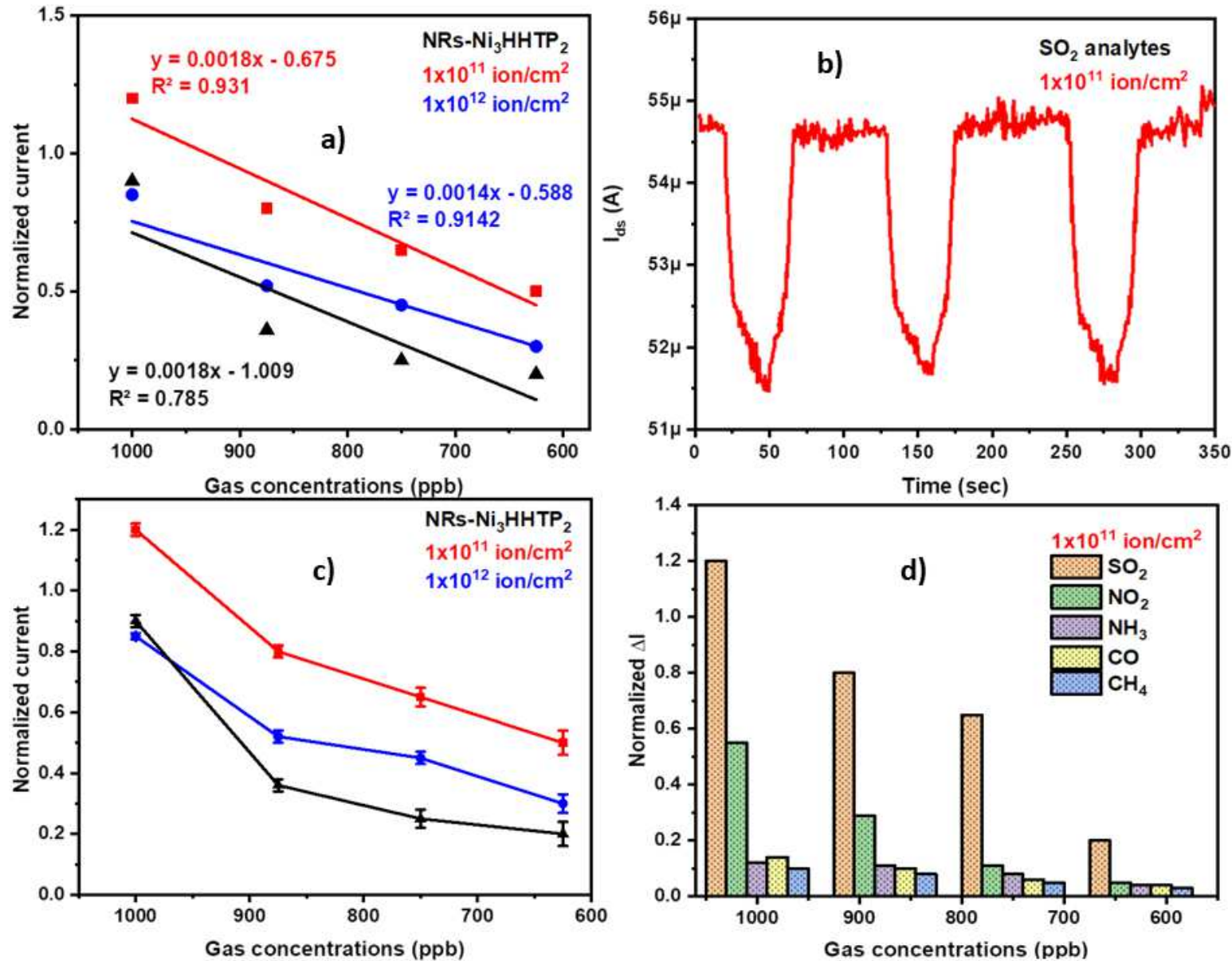

Figure 5: a) plot of concentration versus normalized current with R-squared value b) repeatability for $\mathrm{SO}_{2}$ analytes c) standard error bar and d) selectivity performance of $\mathrm{C}^{+12}$ ion irradiation with fluence $1 \times 10^{11} \mathrm{ion} / \mathrm{cm}^{2}$ sensor towards various gases.

The standard error bar is one of the crucial points in sensor properties. The calibration plot is shown in figure 5-c. It exhibited lower deviation at higher concentration of $\mathrm{SO}_{2}$ analytes whereas higher deviations at lower concentrations. The cross selectivity performance of SHI irradiated $\mathrm{MOF}$ for various gas analytes i.e. $\mathrm{SO}_{2}, \mathrm{NO}_{2}, \mathrm{NH}_{3}, \mathrm{CO}$ and $\mathrm{CH}_{4}$ were also investigated. 
It shows good selectivity towards $\mathrm{SO}_{2}$ analytes as shown in figure 5-d. The SHI irradiated MOF ( $\mathrm{C}^{+12}$ ion irradiated with fluence $1 \times 10^{11}$ ion $/ \mathrm{cm}^{2}$ sensor ) exhibits improved selectivity due to increased stacking coefficient for $\mathrm{SO}_{2}$ adsorption in sensing material. The long-term stability was also investigated continuously for 60 days on pristine as well as irradiated sensors as shown in supporting information (SI) figure S1-1. The SHI irradiated MOF exhibited degradation after 25 days. It might be because of creation of more number of defects due to SHI irradiation. The low energy SHI irradiated MOF showed better results than higher energy SHI irradiated MOF in terms of long term stability. The most important parameters in the sensor are response and recovery time, lower detection limit and operating temperature. Table 2 shows comparison of above mentioned sensing parameters of earlier reported work and present work. It can concluded that present work shows better results as compared to earlier reported work. It shows excellent response and recovery time i.e. 20 and $23 \mathrm{sec}$ for $1 \mathrm{ppm} \mathrm{SO} 2$ concentration at room temp (RT) with a lower detection limit of $625 \mathrm{ppb}$.

\begin{tabular}{|c|c|c|c|c|}
\hline Material & $\begin{array}{c}\text { Response/recovery } \\
\text { time (sec) }\end{array}$ & $\begin{array}{c}\text { Lower } \\
\text { detection limit }\end{array}$ & $\begin{array}{l}\text { Operating } \\
\text { temp. }\end{array}$ & Ref. \\
\hline $\mathrm{S}$-doped $\mathrm{SnO}_{2}$ & $30 / 50$ for $100 \mathrm{ppm}$ & $10 \mathrm{ppm}$ & $180^{\circ} \mathrm{C}$ & [33] \\
\hline NiO ZnO nanodisks & $52 / 41$ for $20 \mathrm{ppm}$ & $3 \mathrm{ppm}$ & $240^{\circ} \mathrm{C}$ & [11] \\
\hline $\mathbf{R u} / \mathrm{Al}_{2} \mathrm{O}_{3} / \mathrm{ZnO}$ & $\sim 60 / \sim 360$ & $5 \mathrm{ppm}$ & $350^{\circ} \mathrm{C}$ & [34] \\
\hline $\mathrm{AuNPs}_{\mathrm{N}} \mathrm{SnO}_{2}$ & 34 / 14 for $20 \mathrm{ppm}$ & $500 \mathrm{ppb}$ & $200^{\circ} \mathrm{C}$ & {$[35]$} \\
\hline 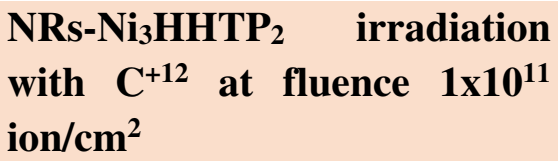 & $\sim 20 / \sim 23$ for $1 \mathrm{ppm}$ & $625 \mathrm{ppb}$ & RT & $\begin{array}{l}\text { Present } \\
\text { work }\end{array}$ \\
\hline
\end{tabular}

Table 2: Presented work sensing parameters compared with recent works of literature

\section{Sensing mechanism}

The sensing mechanism is the key factor to understand the sensing behavior of materials. To understand the sensing mechanism, we have calculated bandgap using Tauc's plot as shown in figure 3-b (1,2 and 3). It shows decrease in banggap after SHI irradiation. After SHI irradiation, defects, free radicals and ions were created on sites of materials. These defects act as an electron trapper with adsorption of the oxygen species from gas analytes. Moreover, these defect were responsible for adsorbing oxygen species and creating oxygen ions thereby preventing electron-hole recombination rate[36]. This was responsible for decreasing drain current after exposing to gas analyte as shown in figure 6.
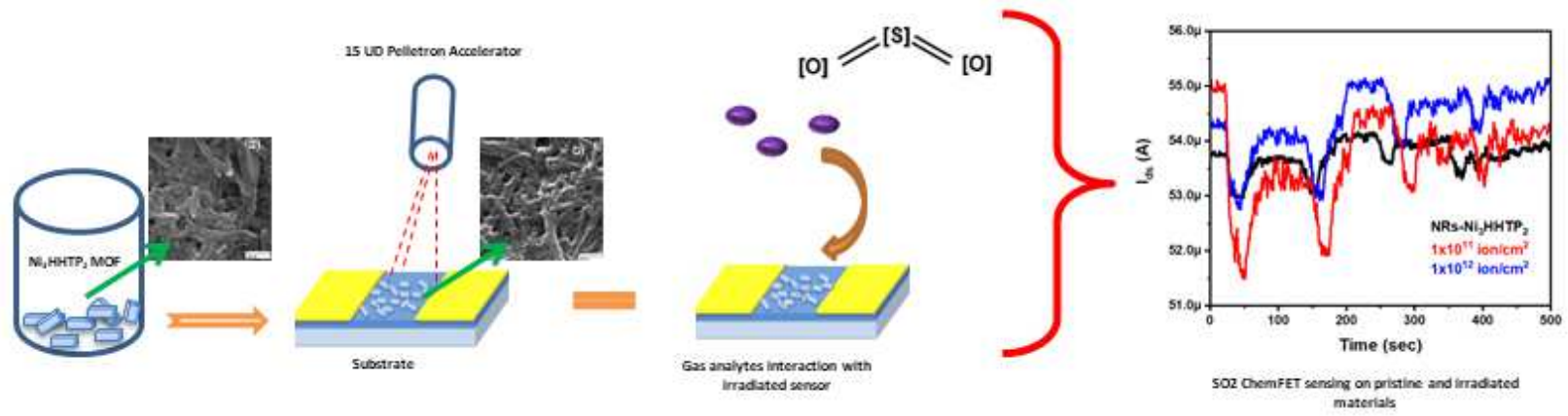

289 Figure 6: schematic for material synthesis, ion irradiation and sensing mechanism 
291

292

293

294

295

296

297

298

299

300

301

302

303

304

305

306

307

308

309

310

311

312

313

314

315

316

317

318

319

320

321

322

323

324

325

326

327

328

329

330

331

332

\section{Conclusions}

The NRs-Ni3 $\mathrm{HHTP}_{2}$ MOFs were successfully synthesized by the chemical method. The SHI irradiation $\mathrm{C}^{12+}$ with fluence $1 \times 10^{11}$ and $1 \times 10^{12} \mathrm{ion} / \mathrm{cm}^{2}$ have induced changes in structural, spectroscopic, morphological, optical and FET properties of NRs-Ni ${ }_{3} \mathrm{HHTP}_{2}$ MOFs. The NRs$\mathrm{Ni}_{3} \mathrm{HHTP}_{2} \mathrm{MOF}$ was amorphized after SHI irradiation which was confirmed by XRD. The XRD pattern exhibits the creation of defects in irradiated materials. The size of NRs-Ni3HHTP 2 MOF decreases with decreasing the surface roughness and form a cluster in irradiated materials which was confirmed from surface morphology by SEM and AFM. The decrease in surface roughness was attributed to discontinuous tracks, which lead to amorphization. The drain current of NRs$\mathrm{Ni}_{3} \mathrm{HHTP}_{2}$ MOFs based FET was enhanced due to the trapping of free mobile carriers after the

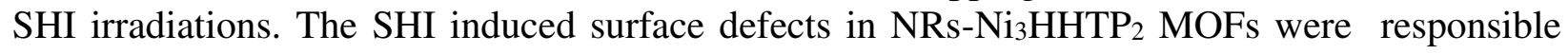
for enhancing sensing properties. Therefore, it can be concluded that SHI irradiated NRs$\mathrm{Ni}_{3} \mathrm{HHTP}_{2} \mathrm{MOF}$ showed improved material properties which were responsible for enhancing sensing properties.

\section{Acknowledgment}

The authors are thankful to the Inter University Accelerator Center (IUAC), New Delhi (UFR-62320 \& UFR-62321) for material science beamline with SEM facilities and financial support. Also thankful to DST-SERB (sanction no. EEQ/2017/000645), UGC-DAE CSR (RRCAT), Indore (Project No. CSR-IC-BL66/CSR-183/2016-17/847), UGC-SAP programme (F.530/16/DRS-1/2016 (SAP-II), dt. 16-04-2016), DST-FIST (Project No. No. SR/FST/PSI210/2016(C) dtd. 16/12/2016), Rashtria Uchachatar Shiksha Abhiyan (RUSA), Government of Maharashtra for providing characterization facilities. Also thankful to Dr. Saif A. Khan, IUAC, New Delhi.

\section{References}

1. Bodkhe, G.A., et al., Field effect transistor based on proton conductive metal organic framework (CUBTC). Journal of Physics D: Applied Physics, 2019. 52(33): p. 335105.

2. Wang, D., D. Jana, and Y. Zhao, Metal-Organic Framework Derived Nanozymes in Biomedicine. Accounts of Chemical Research, 2020. 53(7): p. 1389-1400.

3. Bodkhe, G.A., et al., Selective and sensitive detection of lead $\mathrm{Pb}$ (II) ions: $\mathrm{Au} / \mathrm{SWNT}$ nanocomposite-embedded MOF-199. Journal of Materials Science, 2020. 56(1): p. 474-487.

4. Ingle, N., et al., Sulfur dioxide (SO 2) detection using composite of Nickel benzene carboxylic (Ni 3 $B T C$ 2) and $\mathrm{OH}$-functionalized single walled carbon nanotubes (OH-SWNTs). Frontiers in Materials, 2020. 7: p. 93.

5. Mahadik, M., et al., EDTA modified PANI/GO Composite based detection of $\mathrm{Hg}$ (II) ions. Frontiers in Materials, 2020. 7: p. 81.

6. Nazemi, H., et al., Advanced micro-and nano-gas sensor technology: A review. Sensors, 2019. 19(6): p. 1285.

7. Nowoświat, A. and L. Dulak, Impact of Cement Dust Pollution on the Surface of Sound-Absorbing Panels on Their Acoustic Properties. Materials, 2020. 13(6): p. 1422. 
8. Sayyad, P.W., et al., Chemiresistive SO 2 sensor: graphene oxide (GO) anchored poly (3, 4ethylenedioxythiophene): poly (4styrenesulfonate)(PEDOT: PSS). Applied Physics A, 2020. 126(11): p. 1-8.

9. $\mathrm{Wu}, \mathrm{Y}$., et al., The high-resolution estimation of sulfur dioxide (SO2) concentration, health effect and monetary costs in Beijing. Chemosphere, 2020. 241: p. 125031.

10. Yang, A., et al., Single ultrathin WO3 nanowire as a superior gas sensor for SO2 and H2S: Selective adsorption and distinct IV response. Materials Chemistry and Physics, 2020. 240: p. 122165.

11. Zhou, Q., et al., High sensitive and low-concentration sulfur dioxide (SO2) gas sensor application of heterostructure NiO-ZnO nanodisks. Sensors and Actuators B: Chemical, 2019. 298: p. 126870.

12. Kumar, V. and D.R. Roy, Single-layer stanane as potential gas sensor for NO2, SO2, CO2 and NH3 under DFT investigation. Physica E: Low-dimensional Systems and Nanostructures, 2019. 110: $\mathrm{p}$. 100-106.

13. Tchalala, M., et al., Fluorinated MOF platform for selective removal and sensing of SO 2 from flue gas and air. Nature communications, 2019. 10(1): p. 1-10.

14. El-Said, A.S., et al., Tuning Tailored Single-Walled Carbon Nanotubes by Highly Energetic Heavy Ions. Physical Review Applied, 2020. 13(4): p. 044073.

15. Gupta, H., et al., Defect-induced photoluminescence from gallium-doped zinc oxide thin films: influence of doping and energetic ion irradiation. Physical Chemistry Chemical Physics, 2019. 21(27): p. 15019-15029.

16. Esquinazi, P., et al., Induced magnetic ordering by proton irradiation in graphite. Physical Review Letters, 2003. 91(22): p. 227201.

17. Krasheninnikov, $\mathrm{A}$. and $\mathrm{K}$. Nordlund, Ion and electron irradiation-induced effects in nanostructured materials. Journal of applied physics, 2010. 107(7): p. 3.

18. Raghuvanshi, S., et al., Dual control on structure and magnetic properties of $\mathrm{Mg}$ ferrite: role of swift heavy ion irradiation. Journal of Magnetism and Magnetic Materials, 2019. 471: p. 521528.

19. Ratan, A., et al., Enhanced electrical properties of few layers MoS2-PVA nanocomposite film via homogeneous dispersion and annealing effect induced by $80 \mathrm{MeV}$ Carbon6+ swift heavy ion irradiation. Materials Science in Semiconductor Processing, 2020. 108: p. 104877.

20. Zeng, J., et al., Graphene electrical properties modulated by swift heavy ion irradiation. Carbon, 2019. 154: p. 244-253.

21. Manikanthababu, N., et al., Swift heavy ion irradiation-induced modifications in the electrical and surface properties of B-Ga2O3. Applied Physics Letters, 2020. 117(14): p. 142105.

22. Patil, H.K., et al., Reinforcement of polyaniline and poly-(o-toluidine) with SWNTs and tuning of their physicochemical properties by heavy ion beams. Applied Physics A, 2018. 124(7): p. 491.

23. Patil, H.K., et al. Spectroscopic investigations upon 100MeV oxygen ions irradiation on polyaniline and poly-o-toluidine. in AIP Conference Proceedings. 2018. AIP Publishing LLC.

24. Ochedowski, O., et al., Radiation hardness of graphene and MoS2 field effect devices against swift heavy ion irradiation. Journal of Applied Physics, 2013. 113(21): p. 214306.

25. Bolse, T., H. Paulus, and W. Bolse, Swift heavy ion induced dewetting of metal oxide thin films on silicon. Nuclear Instruments and Methods in Physics Research Section B: Beam Interactions with Materials and Atoms, 2006. 245(1): p. 264-268.

26. Dutta, R. and A. Kumar, $100 \mathrm{MeV} \mathrm{O7+} \mathrm{ion} \mathrm{irradiation} \mathrm{induced} \mathrm{electrochemical} \mathrm{enhancement} \mathrm{in}$ NiBTC metal-organic framework based composite polymer electrolytes incorporated with ionic liquid. Materials Research Express, 2019. 6(8): p. 085305.

27. Sayyad, P.W., et al., Tuning the properties of Fe-BTC metal-organic frameworks (MOFs) by swift heavy ion (SHI) irradiation. Radiation Effects and Defects in Solids, 2020: p. 1-10. 
400

401

402
28. Ingle, N., et al., ChemFET Sensor: nanorods of nickel-substituted Metal-Organic framework for detection of SO 2. Applied Physics A, 2020. 126(9): p. 1-9.

29. Datta, K., et al., Organic field-effect transistors: predictive control on performance parameters. Journal of Physics D: Applied Physics, 2013. 46(49): p. 495110.

30. Ram, J., et al., lon beam engineering in WO3-PEDOT: PSS hybrid nanocomposite thin films for gas sensing measurement at room temperature. Inorganic Chemistry Communications, 2020. 119: p. 108000.

31. $\mathrm{Xu}, \mathrm{H}$., et al., Ag/Ag2S Nanoparticle-Induced Sensitization of Recovered Sulfur-Doped SnO2 Nanoparticles for SO2 Detection. ACS Applied Nano Materials, 2020. 3(8): p. 8075-8087.

32. Mene, R.U., M.P. Mahabole, and R.S. Khairnar, Surface modified hydroxyapatite thick films for CO2 gas sensing application: Effect of swift heavy ion irradiation. Radiation Physics and Chemistry, 2011. 80(6): p. 682-687.

33. $\mathrm{Xu}, \mathrm{H}$., et al., Ag/Ag2S Nanoparticle-Induced Sensitization of Recovered Sulfur-Doped SnO2 Nanoparticles for SO2 Detection. ACS Applied Nano Materials, 2020.

34. Liu, Y., et al., An integrated micro-chip with Ru/Al2O3/ZnO as sensing material for SO2 detection. Sensors and Actuators B: Chemical, 2018. 262: p. 26-34.

35. Liu, L. and S. Liu, Oxygen vacancies as an efficient strategy for promotion of low concentration SO2 gas sensing: the case of Au-modified SnO2. ACS Sustainable Chemistry \& Engineering, 2018. 6(10): p. 13427-13434.

36. Lim, S.K., et al., Preparation of ZnO nanorods by microemulsion synthesis and their application as a CO gas sensor. Sensors and Actuators B: Chemical, 2011. 160(1): p. 94-98. 
Figures
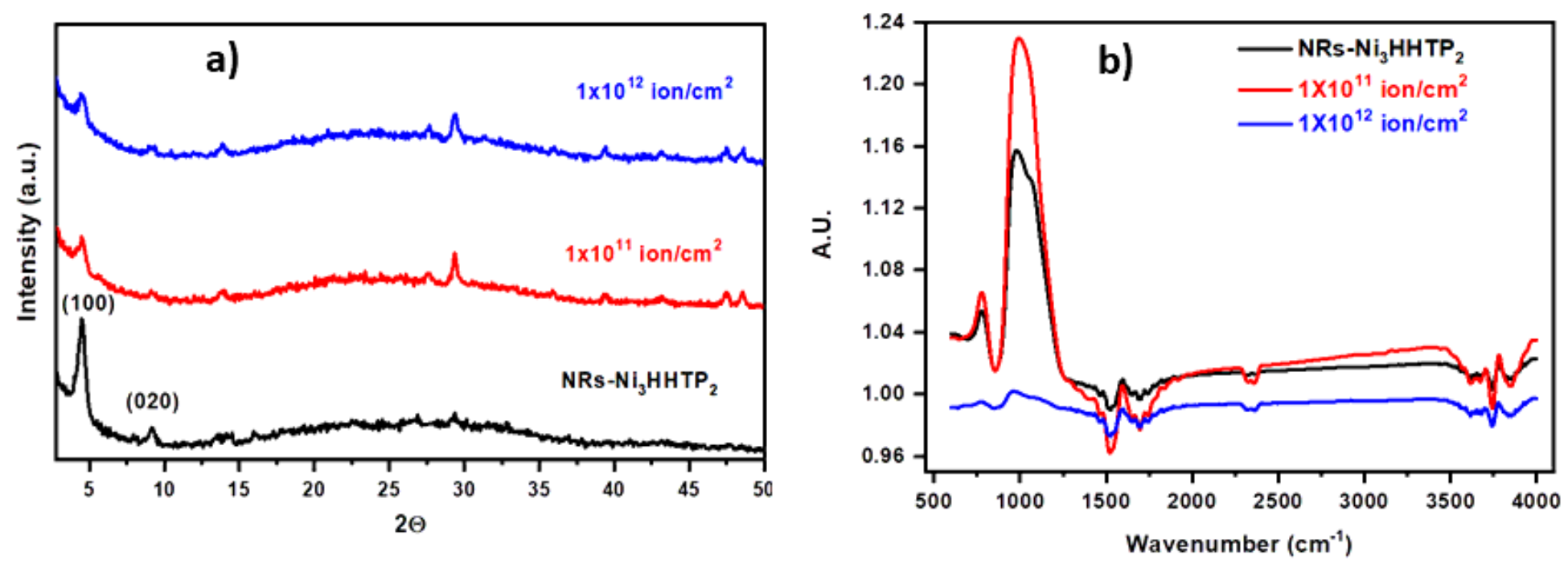

Figure 1

a) XRD patterns and b) FTIR spectrum of pristine (black) and C12+ ion irradiation with fluence rate $1 \times 1011$ ion/cm2 (red) and 1x1012 ion/cm2 (blue) on NRs-Ni3HHTP2 MOF materials. 

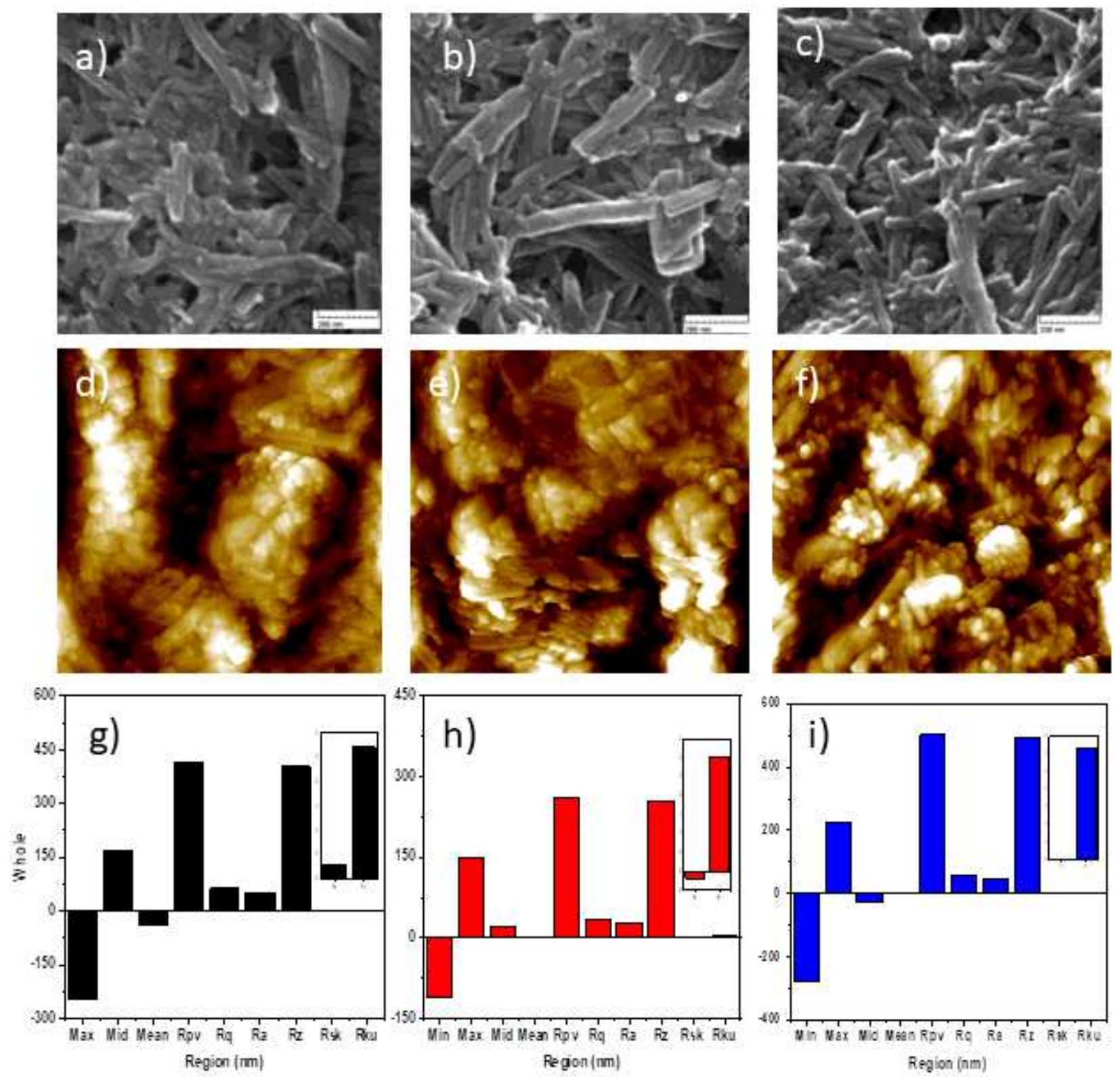

Figure 2

SEM images ( $a, b$ and $c$ ) and AFM images ( $d$, e and $f$ ) with surface roughness ( $g$, $h$ and i) for pristine (black) and C12+ ion irradiation with fluence rate $1 \times 1011 \mathrm{ion} / \mathrm{cm} 2$ (red) and $1 \times 1012$ ion/cm2 (blue) on NRs-Ni3HHTP2 MOF materials respectively. 

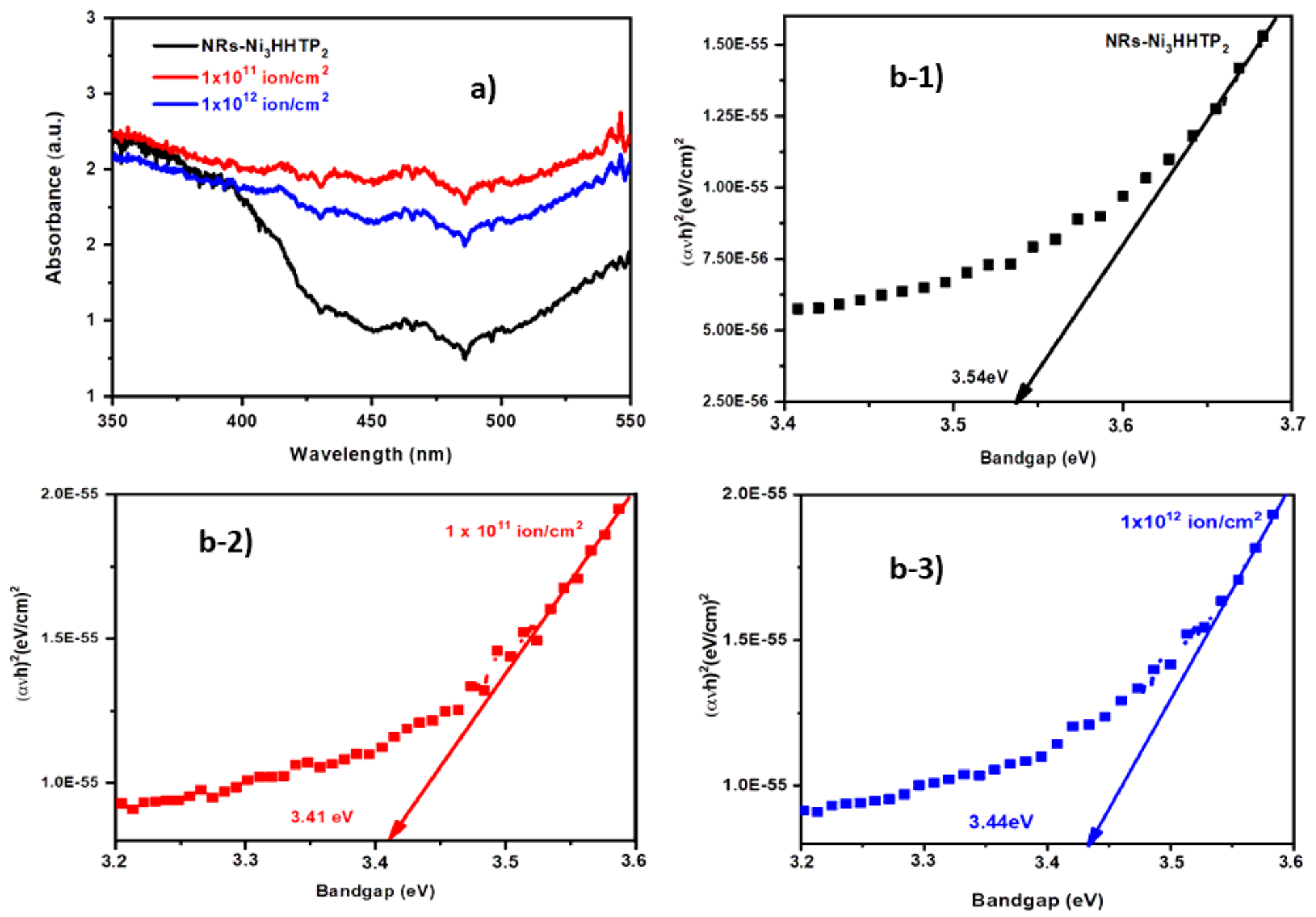

Figure 3

a) UV-Vis absorbance spectra with Tauc's plots (b-1, b-2 and b-3) of pristine (black) and C12+ irradiation with fluence rate $1 \times 1011$ (red) and 1x1012 ion/cm2 (blue) on NRs-Ni3HHTP2 MOF. 

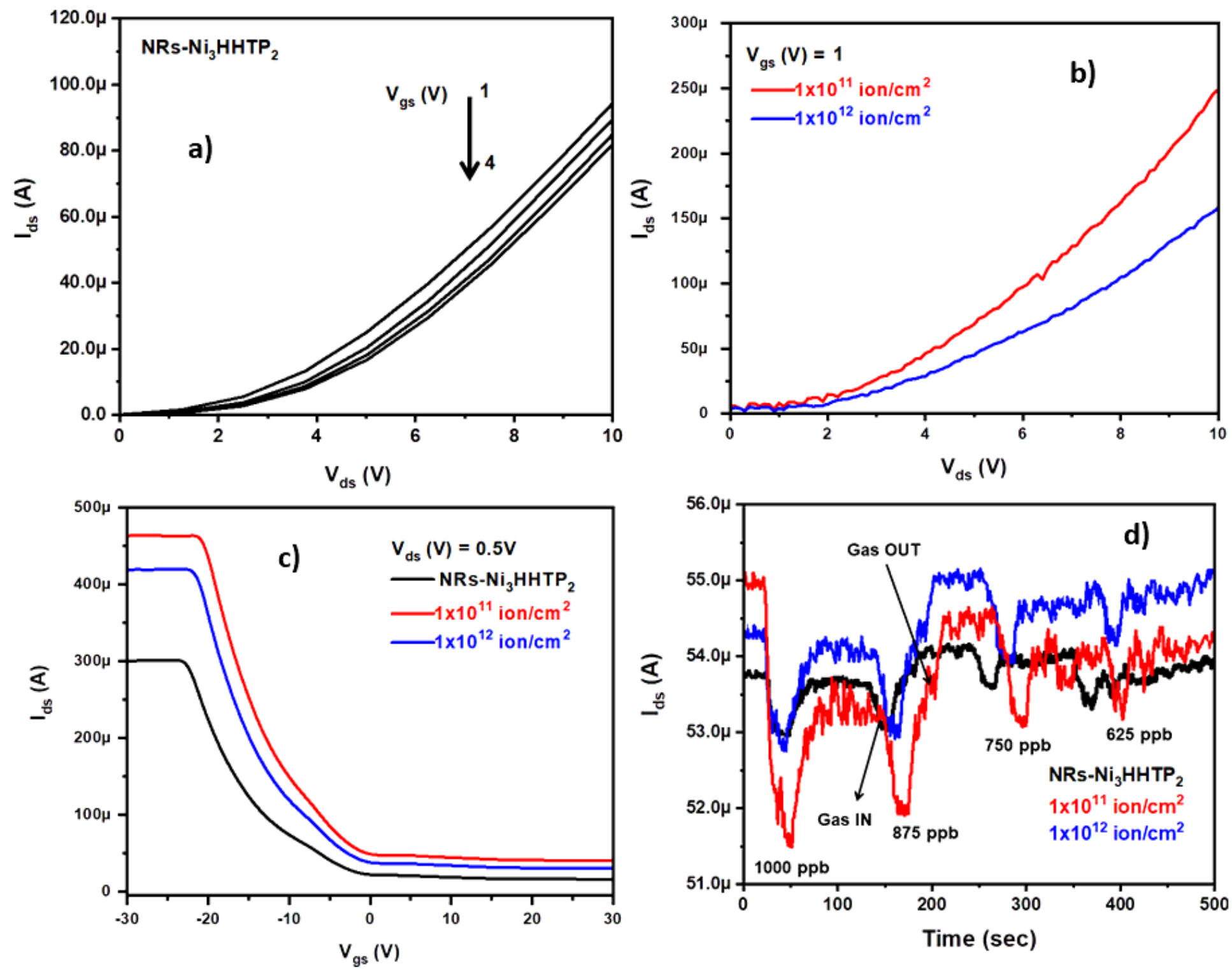

Figure 4

FET measurements i.e. Output characteristics for a) NRs-Ni3HHTP2 MOF and b) after $\mathrm{C}+12$ ion irradiation on MOF material whereas c) transfer characteristics, d) ChemFET sensing for $\mathrm{SO} 2$ analytes. 

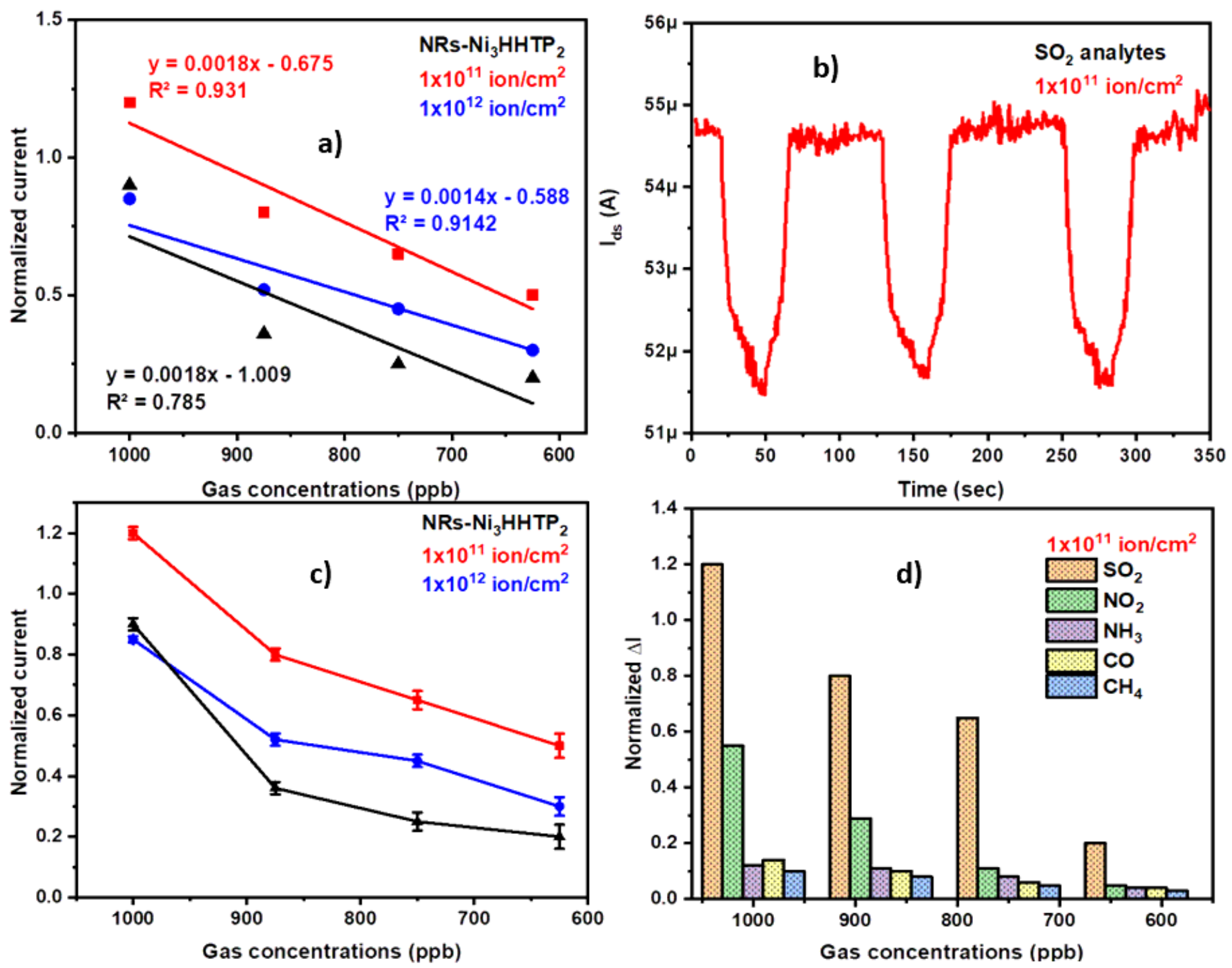

Figure 5

a) plot of concentration versus normalized current with R-squared value b) repeatability for SO2 analytes

c) standard error bar and d) selectivity performance of C+12 ion irradiation with fluence $1 \times 1011 \mathrm{ion} / \mathrm{cm} 2$ sensor towards various gases.
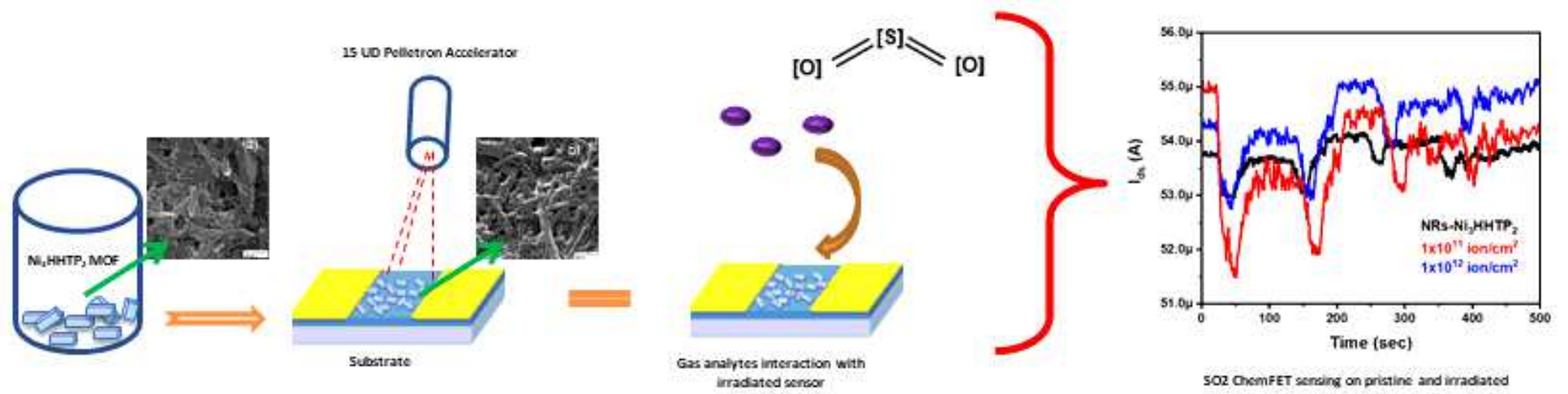

materials

Figure 6 
schematic for material synthesis, ion irradiation and sensing mechanism

\section{Supplementary Files}

This is a list of supplementary files associated with this preprint. Click to download.

- Supportinginformation.docx 